\title{
Hydrocephalus in Congenital Rubella Syndrome: A Case Report
}

\section{Tiwari C, Sandlas G, Jayaswal S and Shah $\mathrm{H}^{*}$}

Department of Paediatric Surgery, TNMC \& BYL Nair Hospital, Mumbai, Maharashtra, India

${ }^{*}$ Corresponding author: Shah H, Department of Paediatric Surgery, TNMC \& BYL Nair Hospital, Mumbai, Maharashtra, India, E-mail: hemanshisshah@gmail.com

Citation: Tiwari C, Sandlas G, Jayaswal S, Shah H (2014) Hydrocephalus in Congenital Rubella Syndrome: A Case Report. J Immunol Infect Dis 2(1): 102. doi: 10.15744/2394-6512.1.202

Received Date: September 10, 2014 Accepted Date: January 02, 2015 Published Date: January 08, 2015

\begin{abstract}
The Congenital Rubella Syndrome is a multisystemic disease and CNS involvement occurs in the form of microcephaly, mental/ motor disabilities, leptomeningitis, encephalitis, vascular damage and retardation of myelination. We report a case of gross noncommunicating hydrocephalus in a neonate of Congenital Rubella Syndrome which is a rare presentation.
\end{abstract}

Keywords: Congenital Rubella Syndrome; Hydrocephalus Leptomeningitis; Greg’s Triad; Expanded Congenital Rubella Syndrome

\section{Introduction}

Congenital Rubella Syndrome is one of the most important and common causes of birth defects. The major defects due to CRS occur in the form of sensorineural, eye defects, cardiovascular defects and brain damage.

Congenital Rubella Syndrome occurs due to in-utero infection of the fetus early in pregnancy by rubella virus. The virus has teratogenic properties and crosses the placenta and infects the fetus where it stops cells from developing or destroys them by direct involvement of viral replication in cell clones during first trimester of pregnancy. When infection occurs within first two months of pregnancy, there are $90 \%$ chances of fetal transmission leading to death or Congenital Rubella Syndrome which reduce to $80 \%$ in 8 to 12 weeks and $50 \%$ in 12 to 16 weeks. Deafness is most common in the latter period of gestation. Congenital anomalies with growth impairment are rare if infection occurs after 16 weeks of gestation. Hydrocephalus in a child suffering from CRS is rare and scarcely reported in the Literature. We report a case of hydrocephalus in a neonate of Congenital Rubella Syndrome (Figure 1).
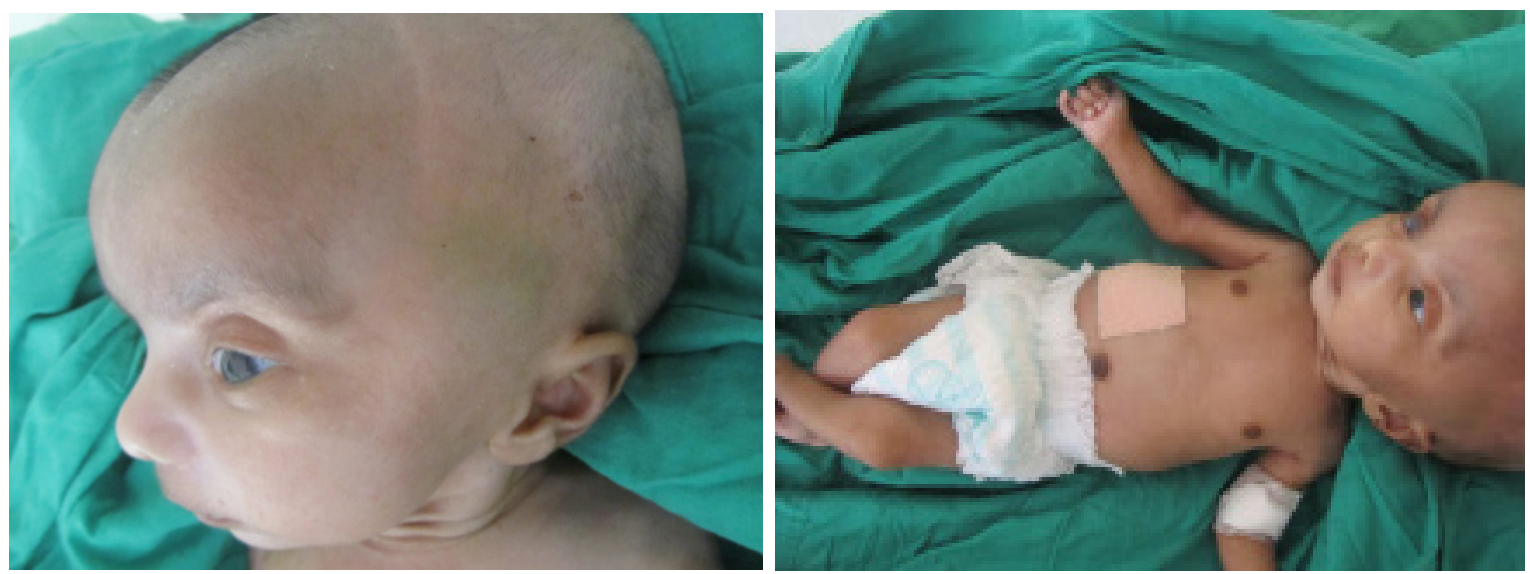

Figure 1: Clinical Photos of the patient.

\section{Case Summary}

A 20 days old, female child with birth weight $2.5 \mathrm{~kg}$ presented with increasing head size and bilateral corneal opacities since birth.

On examination, she had pallor, macrocephaly (Head Circumference- $40 \mathrm{~cm}$, i.e., more than two standard deviations), sutural separation, bilateral corneal opacities and nystagmus, bat-like and low set ears, clinodactyly of the right hand and bilateral flat foot; systemic examination was essentially normal. There were no classical blue-berry muffin rashes or microphthalmia. No history of convulsions.

Routine blood investigations revealed microcytic hypochromic anaemia. IgG for Rubella was positive in high titres (>200AU/ml) in both the mother and the baby. 
Ultrasound (USG) of the skull demonstrated a gross non-communicating hydrocephalus (V: H Ratio-0.9) with thinned out neuroparenchyma and hypoplastic cerebellum. USG Spine revealed a $10 \mathrm{~cm}$ bony defect at cauda equina though the child had no neurosensory symptoms or any external stigmata of spina bifida occulta. USG abdomen was suggestive of mild hepatosplenomegaly.

Computed Tomography (CT scan) of the Brain revealed grossly dilated lateral ventricles with severe thinning of neuroparenchyma with intraventricular haemorrhage in right lateral ventricle and a small posterior fossa with hypoplastic cerebellum and brainstem (Figure 2). No evidence of cerebral calcification. Cerebro-spinal Fluid examination was normal (Figure 3). 2-D Echocardiography revealed Patent Ductus Arteriosus (PDA) and Ventricular Septal Defect (VSD). Ophthalmic examination showed right corneal opacity and left corneal haziness. Fundus examination could not be done because of corneal pathology bilaterally.

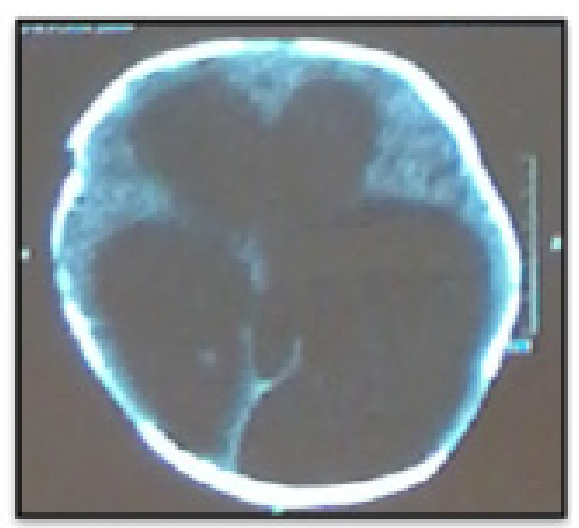

Figure 2: CT Brain showing Hydrocephalus

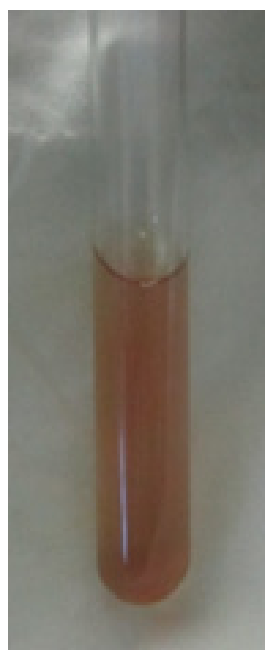

Figure 3: Cerebro-spinal Fluid of the patient.

The child's mother was registered and immunized for Tetanus Toxoid but not for Rubella Vaccine. She had no symptoms during her pregnancy (i.e., fever with rashes). The child was first birth order and was delivered normally. No history was suggestive of any perinatal infection.

Ventriculo-Peritoneal Shunt insertion has been done and the baby is on regular follow-up (Figure 4).

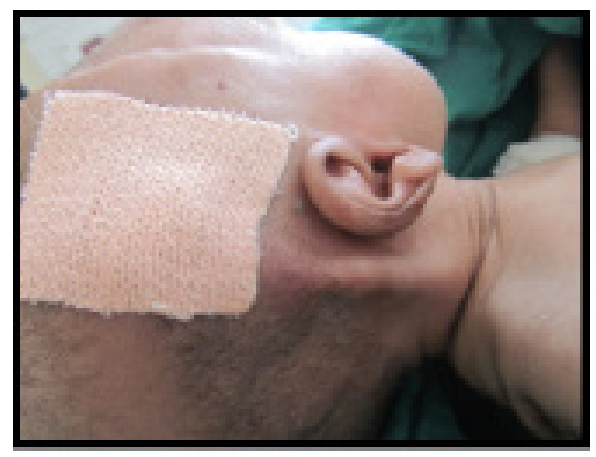

Figure 4: Chamber of Ventriculo-peritoneal Shunt. 


\section{Discussion}

Congenital Rubella Syndrome is an ensemble of anomalies in an infant as a result of primary infection due to Rubella virus in a non-immunized pregnant woman and subsequent fetal infection. Its incidence has greatly decreased after the introduction of Rubella vaccine [1]. It has been estimated that 100,000 infants are affected every year globally [2], more so in the third world countries where immunization with rubella vaccine is not routinely done. The incidence in India is 3 to 5 per 1000 live births [3]. Congenital Rubella Syndrome is probably underdiagnosed [2], especially among the affected children who have sensorineural hearing loss as the only defect.

Increased susceptibility to infection might be inherited as there is some indication that HLA-A1 or factors surrounding A1 on extended haplotypes are involved in virus infection or non-resolution of the disease [4].

Rubella, also known as German measles was first described by the German around mid-18 ${ }^{\text {th }}$ century. Rubella embryopathy was documented early in 1941 by an Australian Ophthalmologist-Sir Norman Gregg from Sydney. Chess et al expanded the classic triad of Congenital Rubella Syndrome to include all other various defects (Expanded Congenital Rubella Syndrome) [5,10].

The classic triad of Congenital Rubella Syndrome (also called the Greg's Triad) [5] involves-Sensorineural deafness ( 58\%), Eye abnormalities like microphthalmia, cataract and retinopathy $(\sim 43 \%)$ and Congenital Heart Diseases like PDA, VSD, Atrial Septal Defects (ASD), Coarctation of aorta $(\sim 50 \%)$. Other manifestations are spleen, liver and bone marrow involvement, mental retardation, microcephaly, Low Birth Weight, hepatomegaly, micrognathia and thrombocytopenic purpura leading to the characteristic Blueberry Muffin Rash. The child is also predisposed to developmental delay, growth retardation, autism, schizophrenia, learning disabilities, diabetes and glaucoma $[5,11]$.

Congenital Rubella Syndrome mostly involves the Central Nervous System, which occurs in the form of persistence of rubella virus in the CNS and neurosensory structures like eyes and ears leading to leptomeningitis, encephalitis, vascular damage and retardation of myelinization. It also affects cell growth. Lethargy, bulging fontanelle, irritability, motor disturbances and dysphasia are common. There may be moderate increases in spinal fluid proteins and cells [6].

Hydrocephalus is a very rare presentation in Congenital Rubella Syndrome with very few cases been reported in literature [7]. The development of hydrocephalus in this child may be attributed to be the sequalae of some form of leptomeningitis and also to the Intraventricular haemorrhage seen in CT Brain. There may be some form of Arnold Chari Malformation in this child in view of the USG Spine finding.

The diagnosis of Congenital Rubella Syndrome is made by increased levels of rubella IgG or seroconversion with IgM antibodies; low avidity of IgG; IgM in fetal blood (after 22 weeks); gene amplification of viral genome in amniotic fluid; or the presence of specific IgM antibodies in the newborn $[8,12]$.

Prognosis depends on the extent of damage. The mortality rate in severely affected neonates is $10 \%$ to $20 \%$. Serious permanent damage occurs in $\sim 50 \%$. About $5 \%$ have some form of thyroid disease in teenage years and $20 \%$ have diabetes by 35 years. Longterm follow-up must continue at least through the first decade of life to detect late-appearing deficits.

\section{Conclusion}

There is no definitive cure of this congenital condition and the management consists of treating the specific anomalies. Prevention is the best cure which can be achieved by aggressive vaccination of all females as per the National Immunization Programme. Females can be vaccinated upto 28 days before pregnancy but being a live vaccine, it is contraindicated during pregnancy [13].

Infants with CRS should be considered infectious until they are at least 1 year old (as they can shed the virus for prolonged periods even up to 1 year of age or longer) or until two cultures of clinical specimens obtained one month apart after the infant is older than three months of age are negative for rubella virus. Infants with CRS should be placed in contact isolation during any hospital admission before age one year or until the infant is no longer considered infectious [9].

\section{References}

1. O’Donnell N (1996) History of the congenital rubella syndrome. J Vocat Rehabil 6: 149-57.

2. World Health Organization (2009) Surveillance Guidelines for Measles, Rubella and Congenital Rubella Syndrome in the WHO European Region. Geneva, Switzerland 1-48.

3. Robertson SE, Cutts FT, Samuel R, Diaz- Ortega JL (1997) Control of rubella and congenital rubella syndrome (CRS) in developing countries, part 2: vaccination against rubella. Bull World Health Organ 75: 69-80.

4. George B. Olson, Peter B. Dent, William E. Rawls, Mary Ann South, JR. Montgomery, et al. (1968) Abnormalities of in vitro lymphocyte responses during rubella virus infections. J Exp Med 128: 47-68.

5. Burgess MA (1991) Gregg's rubella legacy 1941-1991. Med J Aust 155: 355-7.

6. Brown AS (2006) Prenatal Infection as a Risk Factor for Schizophrenia. Schizophr Bull 32: 200-2. 
7. Sriparna Basu, Aditya Kumar Gupta, Ayan Kumar, Poonam Singh, Ashok Kumar (2009) Communicating hydrocephalus in a case of Congenital Rubella Syndrome. J Pediat Neurol 7: 423-6.

8. Peckham CS (1972) Clinical and laboratory study of children exposed in utero to maternal rubella. Arch Dis Child 47: 571-77.

9. Greaves WL, Orenstein WA, Stetler HC, Preblud SR, Hinman AR, et al. (1982) Prevention of rubella transmission in medical facilities. JAMA 248: 861-4.

10. Robert-Gnansia E (2004) Congenital rubella syndrome. Orphanet Encyclopedia1-2.

11. Gale EA (2008) Congenital rubella: citation virus or viral cause of type 1 diabetes? Diabetologia 51: 1559-66.

12. Griffin DE (2007) Alphaviruses Fields Virology ( $5^{\text {th }}$ edition) Lippincott, Williams \& Wilkins Publishers, Philadelphia, USA $1023-68$.

13. World Health Organization (2002) Department of Vaccines and Biologicals. WHO vaccine preventable diseases monitoring system: 2002 global summary. Geneva, Switzerland.

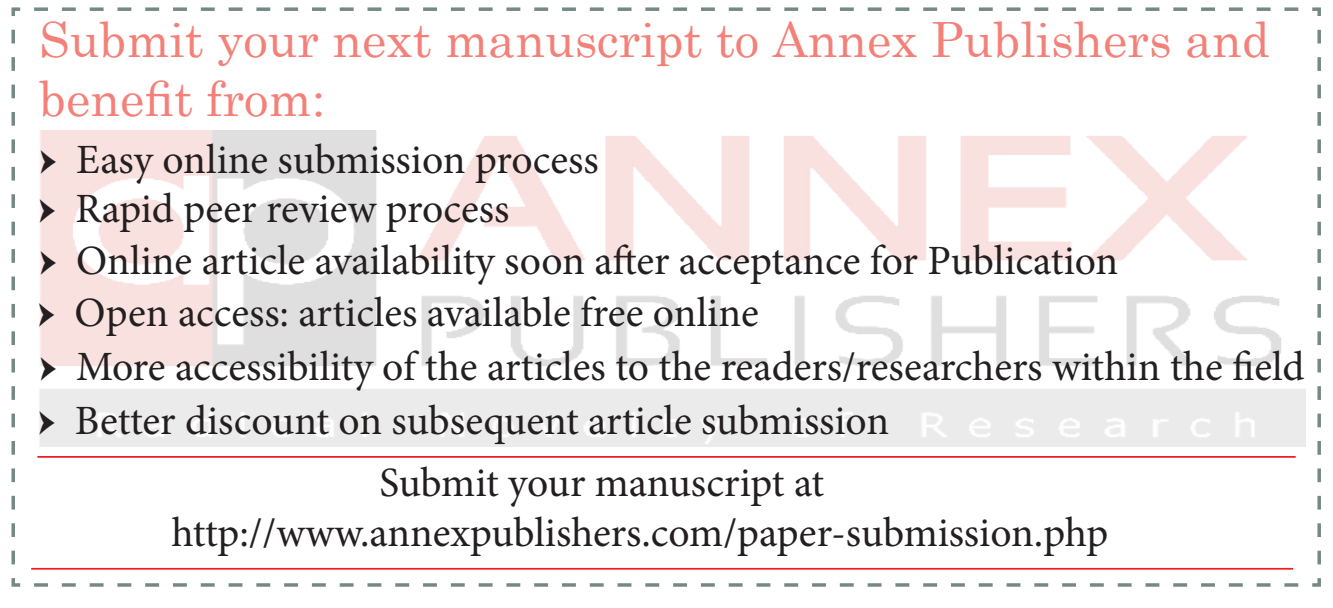

